DOSSIÊ TEMÁTICO: Perspectivas para pensar as cidades: infâncias, educação, democracia e justiça

dol https://doi.org/10.22481/praxisedu.v16i40.6895

\title{
INFÂNCIAS E O DIREITO À CIDADE EM SÃO GONÇALO: INVESTIGANDO A PARTICIPAÇÃO DE CRIANÇAS NA CIDADE
}

\author{
“CHILDHOODS” AND THE RIGHT TO THE CITY IN SÃO GONÇALO: \\ INVESTIGATING THE PARTICIPATION OF CHILDREN IN THE CITY”
}

LAS INFANCIAS Y EL DERECHO A LA CIUDAD EN SÃO GONÇALO: INVESTIGANDO LA PARTICIPACIÓN DE LAS NIÑAS Y LOS NIÑOS EN LA CIUDAD

\author{
Maria Tereza Goudard Tavares \\ Universidade do Estado do Rio de Janeiro - Brasil
}

\begin{abstract}
Resumo: O presente artigo é fruto de pesquisa que vem sendo realizada no âmbito de um projeto mais amplo, denominado "As infâncias e a cidade: investigando componentes territoriais de processos educativos de crianças na cidade de São Gonçalo" (TAVARES, 2010, 2016, 2018). Nesta interrogamos se componentes territoriais da cidade de São Gonçalo produzem impactos nos processos educativos de crianças das classes populares no município. A pesquisa vem complexificando relações que envolvem infâncias e o direito à cidade, pensando-os nos debates que vêm se intensificando nas Ciências Sociais, bem como no Campo Educacional, sobretudo nos estudos da Sociologia da Educação e Estudos Sociais da Infância, direcionando-se, de modo mais substantivo, à problemática das infâncias na cidade. Assim, ao investigarmos trajetórias urbanas e circuitos de educabilidade de crianças dos bairros delimitados na pesquisa, percebemos a existência de uma zona de indeterminação que atravessa o emaranhado da vida social, repercutindo nas práticas e nos circuitos da vida urbana mais ampla, não somente nos equipamentos escolares. Do ponto de vista do horizonte epistemológico, pensamos ser necessário aprofundar a concepção da pesquisa como uma experiência de conhecimento. Em nosso estudo, aprofundamos a concepção de que a cidade, mais do que um conceito, é um campo de práticas. Vale dizer, de práticas infantis de conhecimento, leituras, representação e apropriação do espaço urbano, o que implica elaborar um plano de investigação mais aberto, que ao produzir linhas de força múltiplas, continue a nos instigar a pensar de forma plural a questão das infâncias na cidade.
\end{abstract}

Palavras-chave: Direito à cidade. Infâncias. Pesquisa com criança.

Abstract: This article is the result of a research that has been carried out under the perspective of a
broader project, called "'Childhoods' and the city: investigating territorial components of educational
processes of children in the city of São Gonçalo" (TAVARES, 2010, 2016, 2018). In this research we
question if the territorial components of the city of São Gonçalo have an impact on educational processes
of children from the working classes in the municipality. The research has been complexifying those
relationships which involve the childhood and the right to the city, thinking of the children and including
them in the debates that have been intensified, not only in the Social Sciences, but in the field of
education as well, especially in the studies of Sociology of Education and Social Studies of the
Childhood, focusing on the problem of the childhood in the city in a more substantial way. So, as we
investigate the urban trajectories and the circuits of educability of children who come from those 
neighborhoods delimited by the research, we find out the existence of an undetermined zone that crosses the entanglement of social life, reverberating both in the practices and in the circuits of a broader urban life, and not only in the school equipment. From the point of view of an epistemological horizon, we think it is necessary to thoroughly analyse the concept of research as an experience of knowledge. In our study, we deepened the idea that the city, more than a concept, is a field of practices. It is worth mentioning that, children's practices of knowledge, readings, representation and ownership of the urban space imply the elaboration of a more open research plan which, by producing multiple lines of power, might continue to urge us to think of the issue of "childhoods" in the city in a pluralistic way.

Key words: Right to the city. Childhoods. Child research.

Resumen: Resumen: El presente artículo es fruto de una investigación realizada dentro de un proyecto más amplio, denominado "As infâncias e a cidade: investigando componentes territoriais de processos educativos de crianças na cidade de São Gonçalo" ["Las infancias y la ciudad: investigando los componentes territoriales de los procesos educativos de niños y niñas en la ciudad de São Gonçalo"] (TAVARES, 2010, 2016, 2018). En ésta, interrogamos si los componentes territoriales de la ciudad de São Gonçalo tienen impactos en los procesos educativos de las niñas y niños de clases populares del município. La investigación viene complejizando relaciones que involucran a las infancias y al derecho a la ciudad, pensándolas en el marco de los debates que se vienen intensificando tanto en las Ciencias Sociales como en el campo Educacional, sobre todo en los estudios de la Sociología de la Educación y los Estudios Sociales de la Infancia, direccionándose, de modo más sustantivo, hacia la problemática de las infancias en la ciudad. De este modo, al investigar las trayectorias urbanas y los circuitos de educabilidad de las niñas y niños de los barrios delimitados en la investigación, percibimos la existencia de una zona de indeterminación que atraviesa el entramado de la vida social, repercutiendo en las prácticas y en los circuitos de la vida urbana más amplia, no solamente en los procesos escolares. Desde el punto de vista del horizonte epistemológico, consideramos necesario profundizar la concepción de la investigación como experiencia de conocimiento. En nuestro estudio, profundizamos la concepción de que la ciudad, más que um concepto, es un campo de prácticas. Vale decir, de prácticas infantiles de conocimiento, lecturas, representación y apropiación del espacio urbano, lo que supone elaborar un plan de investigación más abierto, que al producir múltiples líneas de fuerza, continúe instándonos a pensar de forma plural la cuestión de las infancias en la ciudad.

Palabras clave: Derecho a la ciudad. Infancias. Investigación con niños.

\section{Introdução: ou para se pensar a cidade como um (con) texto}

Como diz o outro. Que outro? E desde quando ele se chama Outro? Estranho nome, este, que não identifica, não responsabiliza, não consta de nenhum registro civil: Outro nascido em tal data, em tal lugar, do sexo masculino. Por que nunca se diz: Como diz a outra? A Outra não diz nada, limita-se a ouvir o Outro, se é que ouve? (Carlos Drummond de Andrade, 1979).

Viver nas cidades hoje é a realidade de mais de $90 \%$ de todos os brasileiros e brasileiras (IBGE, 2010). Segundo os números oficiais dos últimos censos demográficos nas grandes cidades brasileiras denominadas de megalópoles, como São Paulo, Rio de Janeiro, Porto Alegre e outras, vivem milhões de pessoas, o que torna essas cidades verdadeiros formigueiros humanos. 
O Estado do Rio registra a maior taxa de urbanização do Brasil, tendo $91 \%$ de sua população vivendo em cidades (IBGE, 2010). Essa grande concentração demográfica, ocorrida especialmente nos últimos 30 anos, relaciona-se com os complexos processos de transformação territorial advindos do nosso modelo de desenvolvimento capitalista concentrador, de sua ação perversa nas áreas rurais.

O processo acelerado de urbanização brasileira vem atingindo nesse começo de século índices de insuportabilidade da vida nas cidades, agravando a desigualdade urbanística como expressão da apropriação desigual do espaço territorial, produzindo diversas formas de violência que atingem a todos, independentemente de seu contexto espacial. As inúmeras passeatas, marchas, manifestações, bem como os intensos movimentos de rua (pacíficos e/ou violentos) em junho de 2013, em todo o país, sobretudo nas grandes metrópoles, tais como Rio, São Paulo, Belo Horizonte, Porto Alegre, e também em cidades sem maior tradição de manifestação popular, foram evidências concretas da "insuportabilidade" da vida nas metrópoles, bem como da necessidade premente de discutir a questão urbana e o direito à cidade (LEFEBVRE, 1991).

Como consequência de estudos no campo das políticas públicas de Educação Infantil, vimos desenvolvendo pesquisas de forma colaborativa com professoras da Universidade do Estado do Rio de Janeiro, estudantes de iniciação científica do curso de Pedagogia e Geografia e professoras de Unidades Públicas de Educação Infantil (UMEI’s) e Creches públicas do município de São Gonçalo, no estado do Rio de Janeiro.

As referidas pesquisas intencionam, de modo mais amplo, contribuir para processos formativos de estudantes de diferentes licenciaturas e professoras da pequena infância, fundamentando-se em duas questões políticas e epistêmicas centrais: o direito da criança à cidade como uma questão central a ser discutida e (re)conhecida nas instituições de educação infantil e o desafio ético, teórico e metodológico de realizar pesquisas com crianças (ALDERSON, 2005; BARBOSA, 2014; TAVARES, 2003, 2010, 2016, 2018).

Nesta perspectiva, a citação utilizada como epígrafe introdutória do presente texto é emblemática do lugar complexo ocupado pelas infâncias na contemporaneidade. Acompanhamos, meio que nocauteados pela velocidade das transformações cotidianas, a tensão entre os inúmeros discursos estruturados sobre as diferentes infâncias e as condições materiais, objetivas e subjetivas, nas quais essas múltiplas infâncias concretamente se realizam, principalmente nos espaços institucionalizados de Educação Infantil.

O escritor Carlos Drummond de Andrade, em seu poema O Outro (1979), registra de maneira irônica o fato de sempre se falar em nome do outro, sem jamais especificar quem é 
esse outro, observando de forma bastante irreverente que nunca se fala em nome da outra. Neste texto, escolhi falar dessa outra que estamos nomeando como crianças das classes populares, as que vivem em periferias urbanas, aquelas que apesar de infans - sem fala, ousam falar, se falam e são falados por nós, professoras e pesquisadoras das infâncias. Buscaremos no presente texto falar dessa outra, recorrendo às vozes daqueles que dialogam com elas em seus estudos, pesquisas e trabalho cotidiano nas instituições educativas.

Em São Gonçalo, município bastante populoso do Estado do Rio de Janeiro, e território de nossas pesquisas interessadas, a pluralização das experiências infantis, os diferentes modos de ser criança, bem como a heterogeneidade da infância como categoria geracional, vêm colocando questões nodais para as diferentes agências sociais reguladoras da infância, como o Estado, a família, a escola, os massmedia. No caso da escola da pequena infância, sobretudo no interior de suas práticas cotidianas, amplia-se a perplexidade daqueles e daquelas que apresentam dificuldades para compreender o movediço estatuto contemporâneo da infância: os/as professores/as e demais profissionais que atuam na Educação Infantil.

Etimologicamente a palavra infância deriva-se do latim infant que significa aquele que não fala, aquele que vem sendo falado pelos diferentes discursos e saberes, sejam estes saberes médicos, jurídicos, psicológicos, pedagógicos, midiáticos, pelos estudos sociais da infância etc. Porém, no terreno concreto, miúdo da vida cotidiana, multiplica-se a polifonia das vozes infantis: a criança reivindica a sua saída dos bastidores do cenário sociocultural, demandando também o seu reconhecimento como ator social (FARIA; FINCO, 2011). Assim, em vez de ser sem linguagem, a criança pequena teria cem linguagens, como nos provoca a pensar o educador italiano Lóris Malaguzzi (1999).

Deste modo, intencionamos no corpo do artigo problematizar um conjunto de questões epistêmicas, políticas e éticas derivadas de pesquisas com crianças da pequena infância, discutindo trabalhos investigativos que atravessam o direito à cidade de crianças que vivem e produzem suas educabilidades em periferias urbanas, especialmente na cidade de São Gonçalo, o segundo maior município em densidade populacional do Estado do Rio de Janeiro, e território físico-geográfico de (re)invenção cotidiana da infâncias que nos propomos a pesquisar e a compreender. Assim, mesmo que ainda de um modo introdutório, devido à provisoriedade dos resultados de nossas pesquisas, estaremos intencionando um diálogo com a outra, com as infâncias que nos cercam, nos comovem e que nos demandam, sobretudo, atenção, escuta sensível (BARBIER, 1985) e capacidade de compreensão. 


\section{Decifra-me ou devoro-te: por que ler e escrever a cidade com as crianças pequenas?}

Em diferentes contextos da história humana, as cidades têm sido estudadas e representadas por inúmeros pensadores nas diversas áreas do conhecimento. Lugar do simbólico, onde se produz a história, cenário das tramas humanas, a cidade pode ser lida, segundo Machado (2002, p.213), como: "Macrocosmo social, encontro de funções e sinergia de criações, texto e discurso, a cidade atravessa as ciências humanas e fecunda artes e letras como questão (o que é a cidade?) e como problema (Por que a cidade?) ".

Em nosso longo processo de pesquisa na rede escolar de São Gonçalo, desde 1998, com o início do percurso de doutorado, e finalizado com o trabalho da tese "Os pequenos e a cidade: o papel da escola na construção de uma alfabetização cidadã”( TAVARES, 2003), tomar a cidade como um livro de espaços, cujas práticas e relações sociais nos parecia epistemicamente importante investigar e ler com os sujeitos escolares, implicou a complexificação do conceito de alfabetização para além de sua acepção usual na cultura escolar. Isto é, implicou tomarmos a "cidade como um problema" como nos desafia Machado (2002).

Do ponto de vista dos estudos realizados, venho afirmando que ler o mundo é também ler o espaço. Isto implica pensá-lo como fruto da construção social e histórica da ação humana. Assim, ler o mundo é estudar a sociedade; é estudar o processo de humanização a partir do território usado, conforme nos ensina Milton Santos (1996). É na contemporaneidade, especialmente, estudar as relações sociais com e na cidade, pois por ser a cidade um meio técnico-científico-informacional (SANTOS, 1996) por excelência, seria um lócus da densidade comunicacional, uma arena cultural, espaço de conflitos, disputas e negociações (TAVARES, 2003).

Um outro conceito importante, e que vem sendo trabalhado no desenvolvimento de nossa pesquisa, é o de educabilidade utilizado por Paulo Freire $(1979,1990)$ e Nestor López (2008). Na concepção de Paulo de Freire, o conceito de educabilidade vai além do direito à educação formal, englobando principalmente a construção de saberes e práticas que possibilitam mudanças na realidade tanto do (a) educador (a) como na relação com as próprias crianças. A educabilidade corresponderia a um saber construído a partir do conhecimento da realidade histórico-social, da realidade espacial concreta, bem como do conhecimento intercambiado entre todos os sujeitos que estão de alguma forma se relacionando no contexto social mais amplo.

Nessa perspectiva, podemos entender que o saber/conhecimento não é produzido apenas na relação escolar: professor/a, crianças e objetos do conhecimento. Mas é construído em 
contextos muito mais amplos, nos quais podemos incluir os contextos familiares destas crianças, os diferentes adultos com os quais se relaciona, os seus pares preferenciais nos diferentes espaços de brincadeiras, e por que não, nas relações construídas nos diferentes espaços vivenciados pelas crianças na cidade.

Em nossa pesquisa, vimos aprendendo que o espaço físico e territorial vivenciado pelas crianças pequenas em muito influencia a construção de seu modo de ser, de seus saberes e concepções de mundo. Neste sentido, podemos dizer que para Paulo Freire (1990) a educabilidade é um processo político e epistêmico, no qual os espaços praticados pelas crianças, mesmo não sendo espaços institucionalizados como as escolas de Educação Infantil e/ou creches, possibilitam a construção de culturas infantis (CORSARO, 2009). O conceito de educabilidade nos parece favorecer um campo simbólico e material no qual as crianças pequenas podem construir identidades e relações de pertencimento com o território vivido.

Em nossa pesquisa tem sido fundamental entender como este processo "de pensar e pensar-se na cidade" (TAVARES, 2003) ocorre também nas escolas da pequena infância, já que as pré-escolas e creches em São Gonçalo não são ilhas isoladas das influências que o território da cidade pode propiciar. A escola de Educação Infantil é um dos importantes componentes territoriais da cidade gonçalense, sendo possível compreender que a sua visibilidade e presença na cidade, de modo geral, provoca um impacto cultural/relacional e uma significativa mudança comportamental na imagem das infâncias no espaço público.

Com a presença da criança pequena na cidade, em suas práticas espaciais e deslocamentos a "caminho da escola", também é visibilizado o despreparo da própria cidade frente às demandas infantis por transporte, por segurança, por calçadas e espaços arborizados, pelo direito de ir e vir, pelo seu direito à cidade de forma mais ampla.

A partir dessas questões, vimos considerando fundamental em nossa investigação a desnaturalização sobre o significado e o impacto das crianças pequenas usarem os territórios da cidade, bem como investigar o que pensam, conhecem, representam, desconhecem sobre o caminho da escola: o que as crianças pensam sobre o espaço de suas pré-escolas e creches? Como experimentam o caminho de seus bairros até a entrada de sua pré-escola? Quais são os seus contextos e espaços de descobertas? O que elas pensam sobre a sua rua? O seu bairro? Seus espaços de brincadeiras? De que têm medo e insegurança? Quais são os territórios das infâncias na cidade? Por isso, buscamos em López (2008) entender que a questão da educabilidade pode ser lida como a capacidade da criança de participar de processos de discussão do direito à cidade (LEFEBVRE, 1991), de expandir as suas experiências nos diferentes espaços da cidade, sendo esta compreendida também como um agente produtor de 
espaço que gesta e aporta sentidos às suas espacialidades, produzindo espaços e territórios infantis na cidade.

Para aprofundar essas e outras questões políticas epistêmicas da pesquisa sobre infância e cidade, vimos buscando um diálogo atento com escritos da filósofa alemã Hannah Arendt, principalmente com a sua conviç̧ão de pensar a criança como um recém-chegado. A referida autora escreveu em 1961 um ensaio sobre "A crise na educação" - no qual, em nossa leitura crítica, fez uma análise muito contundente de como a crise no mundo acabara por afetar a educação, bem como a relação entre a infância e a escola da infância.

Ainda no artigo citado, para Arendt a educação precisa ser assumida como uma responsabilidade social com os pequenos e sua inserção no mundo social mais amplo. A autora exemplifica a questão da falta de cuidado com o recém-chegado, por exemplo, no evento de Little Rock, nos anos 1950, nos EUA, quando uma adolescente negra teve que ser escoltada para poder entrar na escola no início do processo de abertura das escolas públicas para crianças negras. Arendt fez uma dura crítica aos adultos que, sendo responsáveis pelas crianças, deixaram que os problemas destinados à “esfera pública” as afetassem diretamente, como nesse acontecimento.

Como pensadora da política, Arendt não pretendeu estudar nenhuma solução e prescrições para o campo educacional, e retornando ao recém-chegado, conceito em análise, que significa aquele que nasce para o "mundo" - outro conceito da autora, o qual não se trata do mundo físico, mas, sim, da entrada das crianças na sociedade à qual pertencem. E ainda segundo a autora, caberia aos pais e professores proteger a criança do mundo, e o mundo da criança, isto é, não podemos permitir que concepções adultocêntricas contaminem a infância, bem como não podemos deixar que a renovação que cada criança traz consigo esfacele a tradição (ARENDT, 1961).

Arendt (idem) compreende que cada nascimento traz consigo novas possibilidades, as quais, se desenvolvidas com pré-conceitos, se findam antes que floresçam. A criança pequena tem direitos declarados de importância inegável, que são sistematicamente violados nas sociedades capitalistas ocidentais, dentre eles o direito à cidade - direito este que se não for atrelado a uma cultura pública, isto é, sem o atrelamento às políticas públicas de uso e participação infantil na cidade, além de um forte compromisso das instituições educativas, se torna muito suscetível, impossível de ser efetivamente (e culturalmente) praticado.

Neste diálogo com Hannah Arendt, defendemos que a participação na construção do conhecimento da criança pequena nas escolas de Educação Infantil de forma a abranger o seu contexto citadino não só legaria o sentimento de pertença ao lugar que se vive como também 
poderia educá-la como cidadã responsável pelo "mundo". Isso implica a compreensão da Educação Infantil como um espaço-tempo singular da Educação Básica, caracterizando-se como um portal de boas-vindas às crianças pequenas para adentrar na "esfera pública", conforme nos provoca a pensar Arendt. Assim,

[...]a escola é antes a instituição que se interpõe entre o domínio privado do lar e o mundo, de forma a tomar possível a transição da família para o mundo. Não é a família, mas o Estado, quer dizer, o mundo público, que impõe a escolaridade. Desse modo, relativamente à criança, a escola representa de certa forma o mundo, ainda que o não seja verdadeiramente (ARENDT, 1961, p.10).

Conhecer e explorar os diversos territórios e signos da cidade e praticar formas e modos distintos de usufruir a cidade, de reconhecer-se nela, de realizar o (re)conhecimento dos espaços de produção da vida urbana significa para as crianças pequenas impregnar-se da cultura em seu sentido mais amplo, compreendida como um bem comum, fruto do trabalho humano e da ação do tempo (TAVARES, 2003).

Do ponto de vista geracional, os adultos possuem o domínio do mundo por habitá-lo antes dos pequenos, dos recém-chegados que, ainda, não o possuem por desconhecê-lo. Cabe a eles, diferentes adultos, apresentá-los a esse mundo, e além disso mostrar esse espaço-mundo como possibilidade de construção de si e do outro como comum, como diferente, mas com o estatuto político de igual. Esse talvez seja o sentido mais abrangente do papel da educação e responsabilidade de todos os adultos: darmos boas-vindas ao recém-chegados ao mundo no qual já vivemos.

Essa questão implica discutir como nós (re) apresentamos nossos mundos aos recémchegados, especialmente para que os pequenos tenham como herança o que a autora chama de amor mundi (ARENDT, 1961). Não se trata de pensar a educação das infâncias a partir de uma concepção ingênua e romântica da criança, mas de pensar a criança como capaz e comprometida em assumir a responsabilidade por esse espaço, mesmo com todos os problemas que o mundo possa ter. Implica tomá-lo como seu e lutar por ele, lutar pela vida. E como na maioria das vezes para a criança pequena gonçalense o mundo é a cidade, implica aprender a lutar por ela, para nela viver com dignidade (SANTOS, 1996).

Em suas obras, Hannah Arendt demonstra forte valorização pela História. Assim, a tradição, que é um legado importantíssimo para a autora, constitui um exercício de pensamento, forma de pensar a cidade em diálogo com as suas histórias e memórias; isto é, aprender a ler a cidade implica a capacidade de vivê-la conhecendo suas histórias, sendo constituído por elas. 
A escola da pequena infância, que ao nosso ver poderia ser um espaço maior de experimentações - que poderiam propiciar muitos sentidos às descobertas dos recém-chegados -, ainda carece de impulsionar as crianças à compreensão do sentido das tensões vividas nos espaços públicos, proporcionando-lhes possibilidades de novas discussões que incluam a questão da participação do coletivo infantil, entendendo a importância de se expandir a autonomia destinada às crianças na vida cotidiana.

Do ponto de vista da participação política do recém-chegado, entendo ser crucial que o seu direito à participação possa ser propiciado e respeitado pelos adultos, aqui representados por professores/as e outras pessoas adultas que trabalham na escola da pequena infância, pois (re) apresentar o mundo, papel dos adultos, implica fazer seleção, escolhas, julgamento, silenciamentos.

E na perspectiva do direito dos recém-chegados à cidade, entender como o "mundo", a cidade, o bairro, a rua, a escola se constituíram em seu tempo histórico faz com que o "novo" assuma o "velho" que nele existe e se sinta preparado e livre para pensar/conhecer outras possibilidades. Dessa forma,

\begin{abstract}
A nossa esperança reside sempre na novidade que cada nova geração traz consigo. Mas, precisamente porque só nisso podemos basear a nossa esperança, destruímos tudo se tentarmos controlar o novo que nós, os velhos, pretendemos desse modo decidir como deverá ser (ARENDT 1961, p.12).
\end{abstract}

E ainda,

Na prática, a primeira consequência que daqui decorre é a compreensão clara de que a função da escola é ensinar às crianças o que o mundo é e não iniciálas na arte de viver. Uma vez que o mundo é velho, sempre mais velho do que nós, aprender implica, inevitavelmente, voltar-se para o passado, sem ter em conta quanto da nossa vida será consagrada ao presente (ARENDT 1961, p. $13)$.

Nesse sentido, aprender o direito à cidade, e tornar-se parte de um coletivo que o reivindica, exige processos de compreensão de si e do outro, bem como da importância de se construir uma familiaridade com o espaço compartilhado, entendendo o contexto da produção histórica da cidade, a formação social do lugar, as lutas pelo espaço urbano, na medida em que aprender a ler a cidade como um livro de espaços (TAVARES, 2003) implica todo um trabalho sobre o olhar sobre o mundo. "O mundo mais uma vez não é uma realidade original que atua por trás da visão, da perspectiva, mas, sim, uma evidência, o "lá está" ou “estar lá", que requer sorte ou arte para fazer acontecer" (MASSCHELEIN, 2014, p. 172). E um trabalho para educar 
o olhar seria tomar a cidade com os recém-chegados como um lugar de leituras e experimentações éticas, políticas e estéticas, tomando a cidade como um livro de espaços (TAVARES, 2003).

Na contramão de uma perspectiva instrumental da aprendizagem da leitura e da escrita, entendemos que se na escola de Educação Infantil professores (as) e crianças pudessem problematizar a cidade, lê-la em sua "geografia existencial", descrevendo-a, narrando-a, escrevendo-a de acordo com os diferentes sentidos e linguagens, uma outra experiência alfabetizadora poderia estar sendo construída. Experiência alfabetizadora que implicasse narrar a cidade, tornar o contexto citadino um texto narrativo. Ler a cidade implicaria dela se aproximar, fazendo uso não apenas de forma instrumental, mas através de práticas alfabetizadoras que, ao aprender a ler o espaço da cidade, pudessem conjugar desejo, criação, necessidade e responsabilidade — movimento fundamental, individual-coletivo para se enunciar/construir escolas/cidades mais agenciadas com a vida coletiva, como, por exemplo, as experiências das aulas-passeio pensadas por Freinet (1973), ou as caminhadas realizadas por Jan Masschelein em sua educação formadora de mundo(2014), ou nas marchas do Movimento Zapatista, que faz do seu caminhar perguntando o seu manifesto ético e político-cultural (LABBUCCI, 2013).

Assumimos, assim, o nosso compromisso ético e político e, portanto, epistêmico, de lutar para que a escola da infância, em sua multiplicidade e potência, possa ser um espaço gerador de práticas democráticas, um lugar culturalmente rico, tanto de histórias e memórias distintas como de afeto, cooperação e solidariedade. A escola da infância animada por esses valores, pelo reconhecimento dos recém-chegados como legítimos outros (MATURANA, 1998), poderia se tornar, assim, um campo fértil para que a aventura do conhecimento possa aí se instalar, alimentando sonhos e práticas pedagógicas que possam produzir pensamentos científicos, filosóficos, políticos, artísticos, éticos e humanitários, possibilitando que as diferentes culturas possam ser um dos principais amálgamas de nossas construções identitárias.

\section{Pressupostos éticos, epistêmicos e políticos da pesquisa com crianças: sobre um olhar etnográfico na pesquisa sobre infância e a cidade}

Fundamentada em um longo percurso de trabalho (TAVARES, 2003, 2009, 2010, 2016, 2018) vimos defendendo que a opção pela pesquisa qualitativa de natureza etnográfica possibilita que pesquisadores e sujeitos da pesquisa possam viver a experiência de uma comunidade investigativa (TAVARES, 2003), na qual o longo e minucioso trabalho de campo, 
a produção do que chamamos empiria, longe de ser apenas um espaço de coletas de dados e construção de conhecimentos, nos possibilita um movimento de ação-reflexão-ação coletiva sobre o conhecimento, buscando corroborar o papel de pesquisa como produção intencional de conhecimento numa perspectiva emancipatória, pois, segundo Boaventura de Sousa Santos (2000), todo processo de produção do conhecimento implica e nos desafia aos processos de autoconhecimento, isto é, ao conhecimento de si e do mundo que nos atravessa.

Colocadas estas primeiras questões de natureza epistemológica, afirmamos que muitas são as nossas intenções nas pesquisas que realizamos. Uma pesquisa é sempre motivada por uma multiplicidade de questões, principalmente políticas, éticas e metodológicas, além das questões institucionais e pessoais, tais como financiamento, objetivos e experiência de pesquisa.

Como anunciamos nas palavras iniciais deste artigo, o desafio de buscar pesquisar com crianças, enxergando-as como sujeitos de direitos e coparticipantes do processo de pesquisa, com protagonismo e participação ativa no desenvolvimento da investigação, nos exige pensar e problematizar o caráter ético da pesquisa, a concepção de ciência e a concepção de conhecimento que fundamenta o desenho teórico-conceitual da investigação proposta e a realizada.

A decisão de realizarmos uma pesquisa qualitativa, de inspiração etnográfica, longe de nos proteger como pesquisadoras, nos leva sempre a problematizar o próprio campo científico no qual a pesquisa é produzida, isto é, nos desafia a interrogar alguns parâmetros e procedimentos éticos e conceituais indispensáveis e inerentes à constituição da pesquisa em sua arquitetura aberta, dialógica e plural.

Nesse sentido, o diálogo com autores/as do campo da Antropologia (CANEVACCI, 1993; GRAUE; WALSH, 2003; GEERTZ, 1978; PEIRANO, 1995) e dos Estudos Sociais da Infância (BARBOSA，2014; FARIA; FINCO，2011; MARCHI，2007; SARMENTO; GOUVEA, 2008) tem sido fundamental para a estruturação de nosso movimento investigativo com as crianças e demais profissionais (professoras, merendeiras e inspetores) nas creches e escolas de Educação Infantil em São Gonçalo.

Do ponto de vista epistêmico e metodológico, fazer uma pesquisa de inspiração etnográfica nos exige um trabalho de descrição minuciosa, atenta, nos solicitando, como pesquisadoras, a prestar muita atenção nas coisas fora de nós mesmas, e a nos entregar-nos de modo mais acuidado possível para descrever, registrar e reconhecer o que é novo e original nelas. Assim, expressões como "o olhar etnográfico" ou a "etnografia como um relato de 
experiência" não são autoevidentes, carecendo de muito trabalho meticuloso e treinamento do olhar, da escrita, de muito estudo teórico-conceitual (PEIRANO, 1995).

Segundo Peirano (1995), a etnografia faz parte de uma tradição muito extensa no campo das ciências antropológicas, já sendo pensada e praticada por muitos e distintos autores e linhas teóricas. Podemos dizer, ainda em diálogo com a antropóloga (1995), que, de modo geral, o fazer etnográfico expressa o caráter temporal das explicações, precisamente por ser um trabalho artesanal, microscópio e bastante detalhado. Como prática de pesquisa esse saber-fazer é aprendido no próprio ato de fazê-lo, ou seja, no exercício concreto de realizá-lo, contando sempre com a precariedade do trabalho cotidiano, incluindo a tomada de decisões e escolhas que nem sempre respondem ou dizem respeito a critérios e objetivos equivalentes.

O fazer etnográfico implica muitas vezes fazer a tradução do olhado, do visto (PEIRANO, 1995), produzindo representações concretas e muitas vezes produtoras de marcos autoritários para identidades e alteridades distintas, correndo-se o risco de fixá-las e aprisionálas em identidades fechadas, ou tipologias que podem, inúmeras vezes, produzir preconceitos e generalizações apressadas.

Desse modo, pensar a etnografia como relato de uma experiência traz à tona questões vinculadas à subjetividade do (a) pesquisador (a) e, consequentemente, ao caráter do conhecimento que pode resultar deste processo. A pesquisa pensada como experiência e como um gesto pedagógico (MASSACHELEIN, 2014) nos possibilita assumir o lugar instável e implicado da subjetividade do sujeito que pesquisa e que, portanto, sabe que o texto etnográfico é um experimento incompleto, muitas vezes rasurado pela falta de experiência de quem o produz. Mas o cuidado na descrição e atenção dada à densidade da experiência pode nos permitir que seja efetivado o processo de objetivação e reflexividade por meio do qual a experiência da pesquisa etnográfica torna-se objeto de conhecimento e aprendizado.

Entendo que essas breves reflexões se tornam necessárias para pensar a pesquisa etnográfica como uma forma de olhar e conhecer a cidade com as crianças pequenas. Nesse sentido, pensando a experiência etnográfica com o aprendizado da cidade, entendemos, em diálogo com Walter Benjamin, que ler/aprender a cidade é antes de tudo um "experimentum linguae" (AGAMBEN, 2005). Para Benjamin (1995), o contexto urbano é permeado de poéticas visuais, sonoras, textuais, alegorias que se apresentam como um saber coletivo, um livro de espaços aberto a possíveis leituras/escrituras que, quando compartilhadas como experiências, vivências e modos de conhecimento, podem possibilitar os vínculos dos diferentes sujeitos com suas histórias e histórias da cidade. 
Do ponto de vista mais específico da etnografia com crianças, vimos nos inspirando nos estudos de Barbosa (2014). Para essa autora, três são os aspectos constitutivos da pesquisa de cunho etnográfico com crianças e que, de maneira mais ampla, muitas vezes dificultam e nos exigem coerência epistêmica, ética e política no trabalho investigativo, prioritariamente em seu desenho e intencionalidades.

O primeiro aspecto vincula-se à concepção de ciência inerente ao projeto e a ações da pesquisa de forma mais ampla, especialmente por ser a pesquisa etnográfica uma tipologia de pesquisa aberta e de escopo interativo, bastante flexível em seus procedimentos metodológicos e ferramentas de produção de conhecimento. $\mathrm{O}$ segundo aspecto é que a pesquisa com crianças exige a adoção de um paradigma de conhecimento que as reconheça como sujeito de direitos, como produtoras de cultura e com protagonismo social. $\mathrm{O}$ terceiro aspecto, que deriva do anterior, é a possibilidade e a capacidade de as crianças serem partícipes da pesquisa, tendo direito à publicização de suas imagens, identidades, nomes, bem como a explicitação de suas contribuições intelectuais nos materiais produzidos na pesquisa (BARBOSA, 2014).

Ainda para Barbosa (idem, p.240), é fundamental a elaboração de "um mapa das tensões éticas" que possa contribuir para "a discussão e tornar possível a formulação de diretrizes para a pesquisa com crianças que tenham um caráter ético, mas que não impeçam a existência da pesquisa etnográfica, ou participativa da criança".

Embora tenhamos clareza da complexidade das questões éticas da pesquisa com crianças, bem como dos inúmeros dispositivos necessários à (auto) reflexividade nesta questão, é necessário frisar que, muitas vezes, além dessas intenções, um dos principais objetivos de uma pesquisa é o relacional, isto é, a criação de vínculos afetivos com determinado espaço e com pessoas que circulam/produzem nesse espaço. No nosso caso - trabalho investigativo nas UMEI's em São Gonçalo - temos buscado conjugar tanto os objetivos político, epistemológicos e éticos quanto os relacionais e afetivos.

Em nossa pesquisa, narrar a megacidade polifônica, repleta de signos com as crianças, nos coloca diante de algumas questões epistemológicas: a discussão da cidade, inicialmente associada aos seus aspectos físicos, territoriais, recebe novos matizes quando associada à concepção de uma arquitetura porosa como uma rocha, na qual as construções e as ações das pessoas se entrelaçam umas nas outras, em diferentes circuitos da cidade. Nesse sentido, trazendo o diálogo com Benjamin (1995) e com a sua concepção da porosidade, a cidade é fundamentalmente algo indefinido, pronto e acabado. Como um livro de espaços, as formas da cidade ganham novas formas a partir do dinamismo da vida e dos percursos das pessoas na cidade. 
A cidade de Paris, por exemplo, é vista pelo filósofo como um enorme livro a ser lido"Paris é um grande salão de biblioteca atravessado pelo Sena" (BENJAMIN, 1995, p.195). O olhar benjaminiano flana por ruas e adentra monumentos e toda uma arquitetura grandiosa para nos mostrar um mundo decadente, mas apaixonadamente vivo e repleto de experiências pessoais: "Saber orientar-se numa cidade”, afirma Benjamin, "não significa muito. No entanto, perder-se numa cidade, como alguém que se perde numa floresta, requer instrução" (2000, p.73).

Trazendo essas questões para a metrópole contemporânea, palco e contexto de nossas pesquisas interessadas, entendemos ser fundamental discutir a questão do olhar, tendo em vista a questão de pensar a cidade de São Gonçalo como um (con) texto alfabetizador, reafirmando a nossa concepção da cidade como um livro de espaços que, para ser lido e compreendido, careceria de ser discutido/pensado também na escola da pequena infância:

Me ajuda a olhar! [...] Diego Não conhecia o mar. O pai, Santiago Kovadloff, levou-o para que descobrisse o mar. Viajara para o sul. Ele, o mar, estava do outro lado das dunas altas, esperando. Quando o menino e o pai enfim, alcançaram aquelas alturas de areia, depois de muito caminhar, o mar estava na frente de seus olhos. E foi tanta a imensidão do mar, e tanto o seu fulgor, que o menino ficou mudo de beleza. E quando, finalmente, conseguiu falar, tremendo, gaguejando, pediu ao pai:

-Me ajuda a olhar! (GALEANO, 1991, p.15).

O pedido do menino Diego nos possibilita pensar que, dentre as inúmeras aprendizagens que construímos na vida, também podemos incluir a aprendizagem do olhar. Do olhar à cidade. Igualmente importante é retomar a epígrafe da contracapa do livro "Ensaio sobre a Cegueira" (1995) de José Saramago: "se olha, vê e se vê, repara”. Reparar. Quase sempre o que não fazemos na cidade é reparar: re-parar. É necessário reparar a cidade, aprender a olhá-la. Discutir uma epistemologia do olhar com as crianças pequenas (TAVARES, 2016).

Com Galeano e Saramago, perguntamos: como podemos, como pesquisadoras, ajudar as crianças a olhar a cidade? Como podemos ensinar a cidade como um (con) texto alfabetizador? Como compreender o olhar das crianças sobre a cidade? Como tomar a cidade como um problema político e epistemológico?

Estas são algumas das questões que nos (co) movem a pensar a cidade como uma questão fundamental para os sujeitos escolares, em especial, as crianças da Educação Infantil, entendendo que a experiência urbana pode constituir um pano de fundo comum para alfabetizações mais amplas, vinculadas ao compartilhamento do sensível, daquilo que nos afeta e nos torna (con) viventes na cidade. Nestes termos, as palavras de Walter Benjamin parecem ecoar em nossos ouvidos como um mantra delicado: 


\begin{abstract}
A força da estrada do campo é uma se alguém anda por ela, outra se a sobrevoa de aeroplano. Assim é também a força de um texto, uma se alguém a lê, outra se o transcreve. Quem voa, vê apenas como a estrada se insinua através da paisagem, e para ele, ela se desenrola segundo as mesmas leis que o terreno em torno. Somente quem anda pela estrada experimenta algo de seu domínio e de como, daquela mesma região que, para o que voa, é apenas a planície desenrolada, ela faz sair, a seu comando, a cada uma de suas voltas, distância, belvederes, clareiras, perspectivas, assim como o chamado do comandante faz sair soldados de uma fila. (BENJAMIN, 2000, p.16).
\end{abstract}

Para Benjamin (1994, p. 203), “a cidade é a realização do antigo sonho humano do labirinto". E na leitura de Olgária Matos, filósofa e leitora de Walter Benjamin, “À cidade do absolutamente visível- racionalista e abstrata- se contrapõe a cidade infantil e alegórica, a cidade labiríntica com a qual a criança estabelece pactos secretos" (1989, p. 80). Para Benjamin, o labirinto não se reduz a uma estrutura onírica vertiginosa, ele é na sua essência o próprio avesso das obras culturais dos livros; são os subterrâneos das cidades.

Voltamos, desse modo, a perguntar: como tornar o direito à cidade uma experiência de felicidade, mesmo que clandestina? Como matricular as crianças na cidade, ganhando as ruas como numa manhã de domingo ensolarado? Com tornar a vida na metrópole contemporânea uma experiência de acolhimento para as crianças pequenas, principalmente as crianças das classes populares (TAVARES, 2003) que, justamente por questões de classe, raça e gênero, são as que mais se autorizam estar à deriva na cidade? Estar à deriva no sentido de uma apropriação do espaço da cidade através do caminhar, pelo andar desinteressado nos lugares, explorando ruas, e diferentes pedaços da cidade, “ $\{\ldots\}$ a cidade labiríntica com a qual a criança estabelece pactos secretos" (MATOS, 1989, p.80).

\title{
Cidade, infâncias e leituras da cidade: considerações finais, porém provisórias
}

Quem caminha vive sempre uma experiência binária: de diferença e da igualdade, da individualidade e da sociabilidade, de si e do mundo. (Adriano Labbucci, 2013, p. 54).

Como já afirmado neste artigo, vimos trabalhando com uma metodologia polifônica que se fundamenta, principalmente, nos Estudos Sociais da Infância e da Antropologia urbana (CANEVACCI, 1993), buscando realizar pesquisas de inspiração etnográfica e colaborativa que tematizam a tríade escola da infância, o direito à cidade e alfabetização no sentido de leitura de mundo (FREIRE, 1979). Reiteramos que, do ponto de vista político e epistêmico, três horizontes de questões embasam os nossos itinerários de pesquisa. 
A questão empírica: os componentes territoriais que constrangem ou possibilitam os processos de educabilidade das crianças das periferias urbanas gonçalenses. Os últimos dados do IBGE (2010) e da Secretaria Municipal de Educação de São Gonçalo (2016) parecem reiterar os dados empíricos coletados junto aos moradores entrevistados: vale dizer, não está ocorrendo à ampliação de vagas nas redes públicas de Educação Infantil, isto é, nas creches e pré-escolas municipais. A maioria dos moradores dos bairros periféricos só consegue vagas nas creches conveniadas, que funcionam precariamente à margem das políticas públicas municipais (TAVARES, 2016).

A outra questão implicaria a temática dos direitos. Do ponto de vista do direito à cidade, das políticas urbanas e da urbanidade, ampliam-se a pobreza, o desemprego e a precariedade urbana. Que reverberam no aumento da violência urbana. Morre-se e mata-se muito na cidade São Gonçalo, principalmente nos bairros e loteamentos irregulares, nas áreas pobres e periféricas da cidade (TAVARES, 2016).

Não há como deixar de relacionar essas questões aos processos de educabilidade das crianças pequenas das creches e escolas de Educação Infantil. São justamente elas, as crianças pequenas, que mais sofrem com a escalada da violência urbana em suas ruas e bairros, pois são alvos fáceis das "balas perdidas", tanto dos traficantes quanto da própria polícia, pouco preparada para intervenção nessas áreas de conflitos. Escalada da violência esta que dificulta, melhor dizendo, impede o direito à cidade, pois as crianças e suas famílias são impedidas de se deslocarem de suas casas, muitas vezes impedidas de saírem de casa (em direção à creche ou ao trabalho) após o "toque de recolher" dado pelos traficantes em confrontos sucessivos com a polícia local (Observatório da Segurança RJ, 2019).

A outra questão investigativa diz respeito à questão política ao entender que, na contemporaneidade, vivemos um tempo político e institucional profundamente paradoxal, no qual a celebração formal dos procedimentos e virtudes democráticas, bem como a ampliação institucional dos espaços de participação e de fortalecimento da sociedade civil, entram em choque com o crescente recrudescimento de uma "zona de indiferenciação entre o legal e o ilegal, o direito e o ilícito, entre o público e o privado, a norma e a exceção, produzindo uma inquietante linha de sombra na da vida urbana e suas formas políticas" (TAVARES; LUCCHESI, 2018, p. 28).

Ao investigarmos as trajetórias urbanas e os circuitos de educabilidade das crianças dos três bairros delimitados (Salgueiro, Jardim Catarina e Trindade) na pesquisa, percebemos a existência de uma zona de indeterminação que atravessa o emaranhado da vida social, repercutindo nas práticas e nos circuitos da vida urbana mais ampla, não somente nos 
equipamentos escolares, mas, sobretudo, nas práticas espaciais e nos deslocamentos cotidianos (ou na ausência deles) nesses bairros.

Do ponto de vista investigativo, entendemos ser cada vez mais necessário aprofundar a concepção da pesquisa como uma experiência alteritária de conhecimento. Trata-se de focar e deslocar-se do campo do já sabido para a formulação de novas questões e novos problemas, num esforço de complexificar o olhar para o terreno movediço no qual a realidade-território se move/produz.

Em nossos estudos, vimos aprofundando a concepção de que a cidade, mais do que um conceito, é um campo de práticas (TAVARES; LUCCHESI, 2018). Não se trata de inventar novas teorias e muito menos de domesticar a (s) realidade (s) estudada (s) em alguma matriz explicativa geral. Ao pensar a cidade como um campo de práticas, sobretudo de práticas infantis de conhecimento, representação e apropriação do espaço urbano, busca-se elaborar um plano de investigação mais flexível, mais aberto, que ao produzir linhas de força, nos instigue a pensar de forma plural e inventiva a questão urbana, sobretudo em diálogo com os diferentes profissionais que trabalham nas escolas da pequena infância.

Esse horizonte, para além de ser epistêmico, também é político, nos inspirando à formulação de novas questões, novos problemas de análise, principalmente em diálogo com o mundo da escola da pequena infância, que raramente tematiza a vida urbana como uma questãolimite para os processos de educabilidade infantil.

Em nossas "alfabetizações cotidianas", vimos aprendendo (pesquisadora professores/as e crianças) que a temática dos direitos, dentre eles o direito à cidade, isto é, da criança conhecer seu território e dele usufruir, é uma questão estrutural, de longa duração, que não pode ser invisibilizada na/pela escola da infância.

A cidadania existente entre nós é fruto de relações sociais complexas, conflitivas, construída em meio a combate e negociações. Nessa perspectiva, interrogar as virtualidades do lugar nos permite reconstruir a dialética do local como arena de antagonismos e complementariedades. Desse modo, tanto o governo municipal quanto os movimentos sociais e os espaços institucionalizados de participação e/ou representação na cidade parecem intuir sobre as virtualidades do lugar como espaços de (re)existência e, também, como o conjunto de oportunidade para a disputa de outros projetos de vida urbana.

Essas questões nos ajudam a reiterar que uma condição cidadã é uma aprendizagem cotidiana construída nas diferentes instâncias sociais na qual a escola da infância, por sua natureza histórica e social, representa uma dimensão política fundamental (TAVARES, 2003). 
Assim, a cidadania infantil e o próprio direito à cidade não podem ser tomados e investigados como um dado natural, mas como uma aprendizagem fundamentalmente social, podendo ser tornar nas instituições escolares um estado de espírito, enraizado na cultura (SANTOS, 1996).

Desse modo, o que o trabalho meticuloso e dedicado da pesquisa vem possibilitando afirmar é a riqueza do cotidiano da escola da pequena infância para a educabilidade e a formação de uma "cultura de direitos" (ARENDT, 1995) na qual adultos e crianças possam ser reconhecer como sujeitos e coconstrutores ativos de seus destinos no (s) mundo (s).

\section{REFERÊNCIAS}

AGAMBEN, G. Infância e história: destruição da experiência e origem da história. Belo Horizonte: UFMG, 2005.

ANDRADE, C.D. de. O Outro. IN: Poesia e Prosa. Rio de Janeiro: Nova Aguillar, 1979.

ARENDT, H. A Condição Humana. São Paulo: Forense Universitária, 1995.

ARENDT, H. Reflexões sobre Little Rock. In: ARENDT, H. Responsabilidade e Julgamento. 1. ed. São Paulo: Companhia das Letras, 1959. p. 261-281.

ARENDT, H. A crise na educação. In: Between past and future: six exercises in political thought, Nova York, 1961. 173-196. Disponível em:

http://www.gestaoescolar.diaadia.pr.gov.br/arquivos/File/otp/hanna_arendt_crise_educacao.p df $>$.

BARBIER, R. A Pesquisa-Ação na Instituição Educativa. Rio de janeiro: Zahar, 1985.

BARBOSA, M, C, S. A ética na Pesquisa etnográfica com crianças: primeiras problematizações. Revista Práxis Educativa, Ponta Grossa, V. 9, N.1, P.235-245, jan./jun., 2014.

BENJAMIN, W. Infância em Berlim. IN: Obras escolhidas II: Rua de Mão Única. São Paulo: Brasiliense, 2000.

BENJAMIN, W. Charles Baudelaire - um lírico no auge do capitalismo. Obras escolhidas III. São Paulo: Brasiliense, 1995.

CANEVACCI, M. A Cidade Polifônica. Ensaio sobre a antropologia da Comunicação urbana. São Paulo: Studio Nobel, 1993.

CASTRO, L. R. Subjetividade e Cidadania: um estudo com crianças e jovens em três cidades brasileiras. Rio de janeiro: Sete Letras, 2001.

CORSARO, W. Reprodução Interpretativa e Cultura de pares. IN: MULLER, F.;

CARVAlHO, A. M. (Orgs.). Teoria e Prática na pesquisa com crianças: diálogos com William Corsaro. São Paulo: Cortez, 2009. 
FARIA, A.L. G.; FINCO, D. (Orgs.). Sociologia da infância no Brasil. Campinas, SP: Autores Associados, 2011.

FREINET, C. Para uma escola do povo: guia prático para a organização material, técnica e pedagógica da escola popular. Lisboa: Presença, 1973.

FREIRE, P. Pedagogia do oprimido. Rio de Janeiro: Paz e Terra, 1979.

FREIRE, P. A importância do Ato de Ler em três artigos que se completam. São Paulo: Cortez, 1986.

FREIRE, P.; MACEDO, D. Alfabetização: leitura do mundo, leitura da palavra. São Paulo: Paz e Terra, 1990.

FREIRE. P. Pedagogia da Esperança. São Paulo: Paz e Terra, 1993.

GALEANO, E. O Livro dos Abraços. 2 ${ }^{\text {a }}$ Edição. Porto Alegre: L\&PM,2008.

GRAUE, M. E.; WALSH, D, J. A investigação etnográfica com crianças: teorias, métodos e ética. Lisboa: Fundação Calouste Gulbenkian, 2003.

INSTITUTO BRASILEIRO DE GEOGRAFIA E ESTATİSTICA (IBGE). Censo Demográfico Nacional. Rio de Janeiro, 2010.

LABBUCCI, A. Caminhar, uma revolução. São Paulo: Martins Fontes, 2013.

LEFEBVRE, H. O Direito à Cidade. São Paulo: Editora Moraes, 1991.

LÓPEZ, N. A Escola e o Bairro: Reflexões sobre o caráter territorial dos processos educacionais nas cidades. IN: RIBEIRO, L.C.Q.; KAZTMAN, R. (Org.). A Cidade contra escola? Segregação urbana e desigualdades educacionais em grandes cidades da América Latina. Rio de Janeiro: Letra Capital, FAPERJ, 2008.

MALAGUZZI, L. Ao contrário, as cem existem.IN: EDWARDS, C.; GANDINI, L.; FORMAN, G.(Org.). As cem linguagens da criança: a abordagem de Reggio Emília na educação da primeira infância. Porto Alegre: Artmed, 1999.

MARCHI, R. Os sentidos (paradoxais da infância nas ciências sociais: uma abordagem da sociologia da infância sobre a "não criança" no Brasil.\{s.d.\}: UFSC, 2007(Tese de doutorado). Florianópolis.

MATOS, O.C.F. Benjaminianas: Cultura capitalista e Fetichismo contemporâneo. São Paulo: Editora UNESP, 2010.

MASSCHELEIN, J. O mundo "mais uma vez": andando sobre linhas.IN: MARTINS, F.F.R.; NETTO, M.J.V.; KOHAN, W.O. (orgs.). Encontrar Escola. Rio de Janeiro:

Lamparina/FAPERJ, 2014.

OBSERVATÓRIO DE SEGURANÇA DO RIO DE JANEIRO. Rio de Janeiro, Relatório, Dezembro, 2019.

SANTOS, B. S. A Crítica da Razão Indolente. Contra o desperdício da experiência. Porto: Afrontamentos, 2000.

SANTOS, M. Técnica espaço tempo: globalização e meio técnico-científico informacional. São Paulo: Hucitec, 1997.

SANTOS, M. O Espaço do cidadão. São Paulo: Nobel, 1996. 
SARAMAGO, J. Ensaio sobre a Cegueira. São Paulo: Companhia das Letras, 1995.

SARMENTO, M.J.; GOUVEA, M.C.S. (orgs.). Estudos da infância: educação e práticas sociais. Petrópolis: Vozes, 2008.

SARMENTO, M.J. Visibilidade social e estudo da infância. In: VASCONCELLOS, V.M.; SARMENTO, M.J. (Org.). Infância (in)visível. São Paulo, Junqueira Marin, 2007.

TAVARES, M.T.G. A Infância e a Cidade: investigando componentes territoriais de processos formativos de crianças na cidade de São Gonçalo. Projeto de Pesquisa Prociência UERJ/FAPERJ, Rio de Janeiro, 2016.

TAVARES, M.T.G. A(s) Infância(s) e a cidade: discutindo processos formativos de crianças nos territórios gonçalenses. Projeto de Iniciação Científica, UERJ, Rio de Janeiro, 2010.

TAVARES, M.T.G. Os "pequenos", a Escola da Infância e o Direito à cidade. IN: LOPES, J.J.M. e MELLO, M. B. de. "O Jeito de que nós crianças pensamos sobre certas coisas": Dialogando com lógicas infantis. Rio de Janeiro: Rovelle, 2009.

TAVARES M.T.G. Os Pequenos e a cidade: O papel da Escola na construção de uma alfabetização cidadã. (s.d.):UFRJ, 2003(Tese de Doutorado), Rio de Janeiro, 2003.

TAVARES, M.T.G.; LUCCHESI, J. C. A cidade como um livro de espaços: lendo e pensando a cidade com a(s) infâncias(s)de creches comunitárias do Rio de Janeiro. IN: CARREIRO, H.J.S.; TAVARES, M.T. G.(orgs.). Estudos e Pesquisas com o Cotidiano da Educação das Infâncias de Periferias Urbanas. São Carlos: Pedro \& João Editores, 2018.

\section{SOBRE A AUTORA:}

\section{Maria Tereza Goudard Tavares}

Pós-Doutora em Educação pela UNICAMP, Professora Associada da Faculdade de Formação de Professores da UERJ - Rio de Janeiro - Brasil; Programa de Pós-Graduacão em Educação: Processos Formativos e Desigualdades Sociais -PPGedu/UERJ; Coordenadora do Grupo de estudos e pesquisas das infâncias, formação de professores e diversidade cultural (GIFORDIC). E-mail:mtgtavares@yahoo.com.br

(iD http://orcid.org/0000-0002-9856-5098

Recebido em: 22 de fevereiro de 2020

Aprovado em: 13 de maio de 2020

Publicado em: 01 de julho de 2020 